\title{
THE EFFECT OF ERBIUM: YAG LASER FOR THE FIBRONECTIN EXPRESSION IN GINGIVAL EPITHELIUM WITH NIFEDIPINE INDUCED GINGIVAL OVERGROWTH
}

\author{
Rasha Wagih* and Marwa Mohamed Tawfiq**
}

\begin{abstract}
Background: Gingival overgrowth is one of the side-effects seen as a result of the regular administration of the calcium channel blocker anti-hypertensive drug Nifedipine. Fibronectin (FN), is an adhesive high molecular weight extra cellular matrix glycoprotein which plays an important role in influencing cell growth, adhesion, migration as well as extracellular matrix organization. It also contributes to fibroblast attachment and proliferation, and participates in the regulation of tissue fibrosis. Erbium: YAG laser was approved in 1997 by the U.S. Food and Drug Administration for hard and soft tissue treatment in dentistry. Several studies have been published to demonstrate its efficacy for bone cutting, plaque and subgingival calculus removal, as well as having an antiseptic effect on both soft and hard periodontal tissues. Conventional scaling in combination with Erbium: YAG laser has unexpectedly showed complete healing with normalization of the gingiva, making further surgical treatment for gingival volume reduction unecessary.
\end{abstract}

Objectives: The aim of this study was to investigate the expression of fibronectin and its connection with the development of drug-induced gingival overgrowth. It also explores the effect of Erbium:YAG laser on the amount of fibronectin expression.

Materials and methods: Paraffin embedded biopsies were obtained from 3 groups of patients: 10 normal patients (group C), 10 patients who underwent conventional scaling with surgical correction of gingival enlargement caused by the regular administration of nifedipine (group A), and 10 patients undergoing scaling and surgical removal of the overgrown gingiva due to the regular administration of nifedipine followed by Erbium:YAG laser treatment (group B). All Specimens were stained with Hematoxyin and Eosin to allow analyses of tissue morphology as well as immunostaining to detect fibronectin. Staining intensity in all groups was calculated by semi quantitative analysis. The results were subjected to statistical analysis.

Results: Fibronectin stained less intensely nifedipine induced gingival hyperplasia after one single laser application when compared to gingival over growth without laser therapy.

Conclusion: Erbium: YAG laser could be considered an effective option for the nonsurgical treatment of drug-induced gingival overgrowth which surpassing surgical procedures. It also promoted fast healing and ensured a higher surgical compliance when compared to the conventional techniques.

KEY WORDS: Gingival enlargement, Fibronectin, Immunohistochemestry, Nifedipine and by Erbium:YAG laser.

* Lecturer, Oral Medicine and Periodontology Department, Faculty of Dentistry Cairo University, Cairo, Egypt. Oral Medicine and Periodontology Department, Faculty of Dentistry Badr University in Cairo, (BUC), Cairo, Egypt.

** Lecturer, Oral medicine, Periodontology, and Diagnosis, Faculty of Oral and Dental Medicine Beni-Suef University. 


\section{INTRODUCTION}

The use of the calcium channel blocker and antihypertensive drug Nifedipine over a long period has been shown to have negative effects on periodontal tissues, as they might promote gingival hyperplasia, which in the later phase causes destruction of deeper periodontal tissues. The inevitable consequence of periodontal destruction, is tooth migration and ultimately its loss ${ }^{(2)}$.

Gingival hyperplasia as a result of nifedipine use is usually generalized, and the front teeth interdental papilla are mostly affected. Occasionally, gingival overgrowth might be so florid that the whole tooth becomes covered with the tissue causing difficulty in mastication. ${ }^{(4)}$

Fibroblasts are responsible for connective tissue formation, homeostasis, and repair, and ultimately for the overall architecture of many organs ${ }^{(5)}$

FN is a $500-\mathrm{kDa}$ multidomain, multifunctional cell adhesion glycoprotein identified as a major survival factor for fibroblasts $(6,7,8)$

In fibroblasts, fibronectin (FN) and growth factor (GF) signals converge at the level of the focal contact ${ }^{(9)}$ and are costimulatory ${ }^{(10)}$ for progression through the cell cycle ${ }^{(11)}$. In addition FN and PDGF$\mathrm{BB}$ survival signals for fibroblasts require $\mathrm{FN}$ growth factor binding domains ${ }^{(12)}$.

FN, derived from wound fibroblasts and other local tissue cells, appears in concert with reepithelialization and granulation tissue formation, fibroblast survival (6,7), proliferation (13), and migration through three-dimensional extracellular matrix $(\mathrm{ECM}){ }^{(14)}$. These activities require fibroblast attachment to FN at the Arg-Gly-Asp (RGD) sequence in the tenth FN type III repeat ${ }^{(12)}$.

In the past, surgical remodeling of the overgrowing gingiva was the treatment of choice for these lesions. These procedures were attended with excessive intraoperative bleeding, slow healing, and a low patient compliance. ${ }^{(32,33)}$

The introduction of laser-assisted surgery to general dentistry, represented a major landmark in the surgical management of GO and also in the postsurgical maintenance of good periodontal status in such patients. ${ }^{(34,35)}$. This is mainly due to their excellent performance in excising exuberant oral tissue, their hemostatic action as well as their superior healing ability.

Recent published studies confirm the therapeutic effects of laser therapy as an adjunct to conventional scaling and root planning in the treatment of aggressive periodontitis ${ }^{(36)}$; Moreover, it has facilitated the management of periodontal conditions requiring bone and gingival remodeling, such as surgical crown lengthening, ${ }^{(37)}$ supplementary bone, radicular cementum, and soft tissue debridement as in the case of lateral periodontal cysts ${ }^{(38)}$. In such instances, Diode laser treatment achieved much quicker wound healing.

The noninvasive treatment protocol using Erbium: YAG laser treatmen thas also been shown to be more effective not only for GO treatment, but also for periodontal maintenance in patients with drug induced GO. ${ }^{(39)}$

In this study expression of fibronectin and its association with development of drug induced gingival overgrowth was investigated. We also evaluated the effect of Erbium:YAG laser only on the fibronectin expression in the treatment of such condition without the need of surgical excision of the exceeding gingiva.

\section{MATERIAL AND METHODS}

This study was conducted at the outpatient's clinics of Oral Medicine Department, Faculty of Oral and Dental Medicine, Badr University in Cairo (BUC), Egypt, during the period from (February 2018 to May 2020). 
Patients were subdivided into 2 groups. Patients in group A underwent full mouth disinfection with chlorhexidine $2 \%$ rinses and antibiotic prophylaxis (amoxicillin and clavulanic acid, $1 \mathrm{~g}$ twice a day) during the week before conventional scaling, Group B underwent conventional scaling with Erbium: YAG treatment [key laser 3; kavo-BiberachGermany, wavelength $2940 \mathrm{~nm}$, standard scalpel long tip for contact use with irrigation, $160 \mathrm{~J}$ at 10 $\mathrm{H}(1,6 \mathrm{~W}), 60 \mathrm{sec}$ for tooth] of the pseudo gingival pockets. In group $B$ the treatment was performed by using the laser tip in contact with the internal aspect of the exceeding gingival tissue and with the gingival sulcus at the deepest point of the pseudo pockets. Patients who underwent surgical gingival excision were followed up after 3 weeks.

Biopsy specimens were collected from 10 patients receiving regular nifedipine and treated by conventional scaling only (group A).

Biopsy specimens were collected from 10 patients on nifedipine and treated by conventional scaling with Erbium:YAG treatment (group B).

Biopsies were taken from the gingivae of 10 patients not treated with nifedipine therapy during surgical removal of impacted wisdom tooth (group C).

Written consent was obtained from all patients. Biopsy specimens were embedded in paraffin and cut into $4 \mu$ and placed on positively charged slides, deparaffinized in xylene and rehydrated in graded alcohol. Slides then were preheated to 37 degree Celsius using water bath containing $200 \mathrm{ml}$ of TBS and $200 \mathrm{ml}$ of distilled water.

Sections were immersed in a $37 \mathrm{C}$ water bath containing $0.2 \mathrm{~g}$ trypsin 250 and $0.2 \mathrm{~g}$ calcium chloride dissolved in $200 \mathrm{ml}$ of TBS repeatedly between each step of the immunohistochemistry (IHC) procedure for washing and adjusting $\mathrm{Ph}$.

Slides were immersed in 3\% hydrogen peroxide for quenching endogenous peroxidase activity for
10 min. Broad spectrum LAB-SA detection system from Invitrogen (Cat\# 85-9043) was used to visualize any antigen-antibody reaction that may occur in the tissues, the background staining was blocked by putting 2-3 drops of $10 \%$ goat nonimmune serum blocker on each slide and incubating them in a humidity chamber for $10 \mathrm{~min}$.

Excess serum solution was drained from each slide and 2-3 drops of the primary antibody fibronectin (Visionbiosystems Novocastra cat\# NCL-FIB) were added, The slides were subsequently incubated in the humidity chamber for $1 \mathrm{hr}$. Biotinylated secondary antibody was applied to each slide for 20 min followed by another $20 \mathrm{~min}$ incubation with the enzyme conjugate. DAB chromogen was prepared and 2-3 drops were applied on each slide for $2 \mathrm{~min}$, Then DAB was rinsed and mayer hematoxylin was applied as a counter stain.

Slides were washed and immersed in tap water for $5 \mathrm{~min}$. to enhance counterstaining. They were later dehydrated and cleared to be finally mounted with DPX.

Immunostained specimens were independently evaluated on two separate occasions 48 hours apart by two different pathologists. Calibration was accepted if evaluation for each case were similar

To evaluate the staining for each antibody, the following semiquantitative scale was used: complete lack of staining were scored zero, mild positive identification scored 1 , moderate staining scored 2, and strong staining scored 3.

\section{Statistical Analysis}

Statistical analysis was performed using SPSS version 17.0 (SPSS Inc., Chicago, IL, USA). For statistical evaluations, the groups were evaluated using the paired sample t-test and $\mathrm{P}$ values $<0.05$ were considered statistically significant 


\section{RESULTS}

The hematoxalin and eosin findings showed marked epithelial hyperplasia, longer retepegs as well as marked fibrosis of the sub epithelial connective tissue in group A.

Fibronectin in group (A) showed marked increase in staining within fibrous connective tissue, at the basement membrane of the keratinocytes and within the epithelial cells and the reaction ranged from moderate to deep staining.
Fibronectin staining of specimens from group (B) showed moderate to light staining.

Fibronectin staining of the majority of specimens from group (C) showed negative to light staining and only 2 specimens showed moderate staining.

The semi quantitative analysis results of fibronectin immunostaining for the three groups are summarized in Table (1)
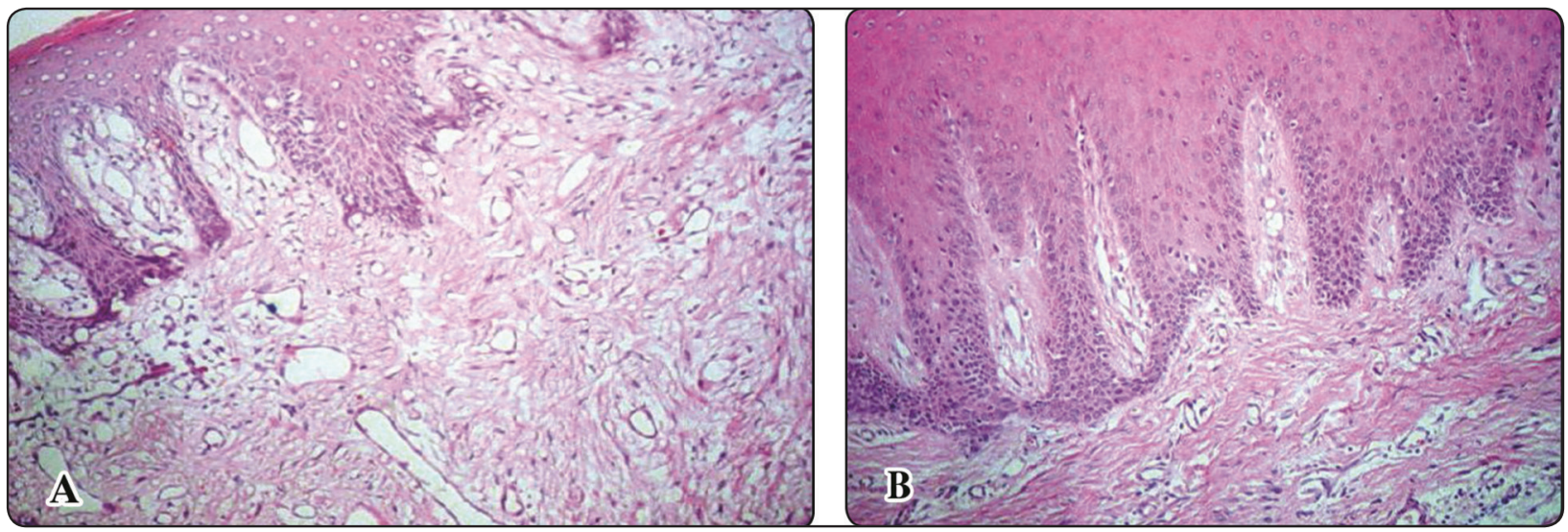

Fig. (1) (a) H\&E x100 in a speciamen taken from group B showing slight epithelial hyperplasia with delicate fibrous connective tissue stroma, while there is increased epithelial hyperplasia and connective tissue fibrosis in spiciamens from group A figure (b) $H \& E$ x 100

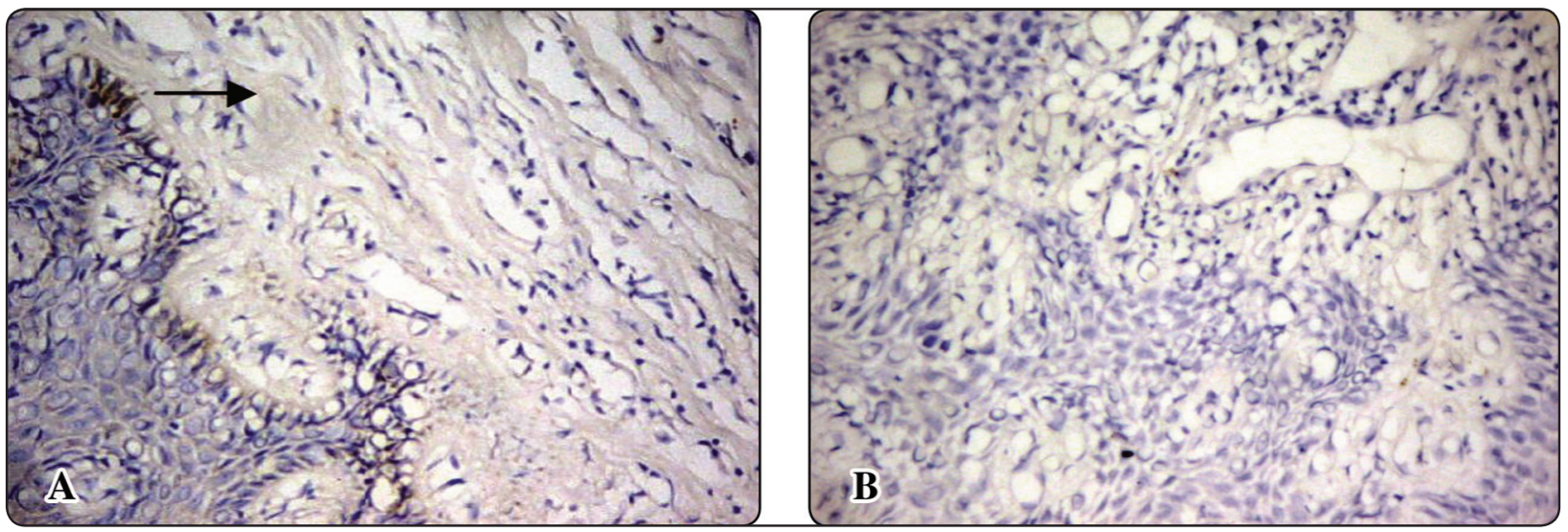

Fig.. (2) (a) Fn x200 showing moderate fibronectin staining at the basement membrane (arrows) group B while in another specimen figure (b) Fnx200there was negative reaction to fibronectin group C. 


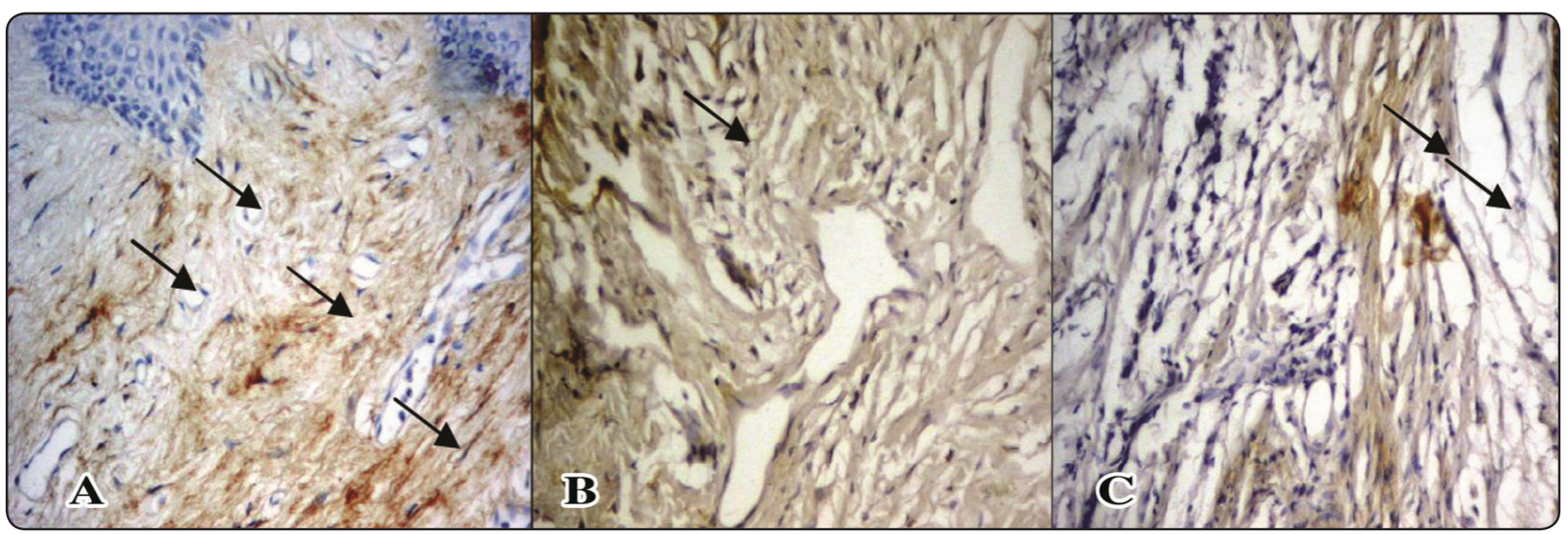

Fig. (3) (a) Fn x200 showing deep staining with fibronectin within fibrous connective tissue (arrows), (b) and (c) Fn x200 arrows pointing at the deep staining within two different cases in group $\mathrm{A}$
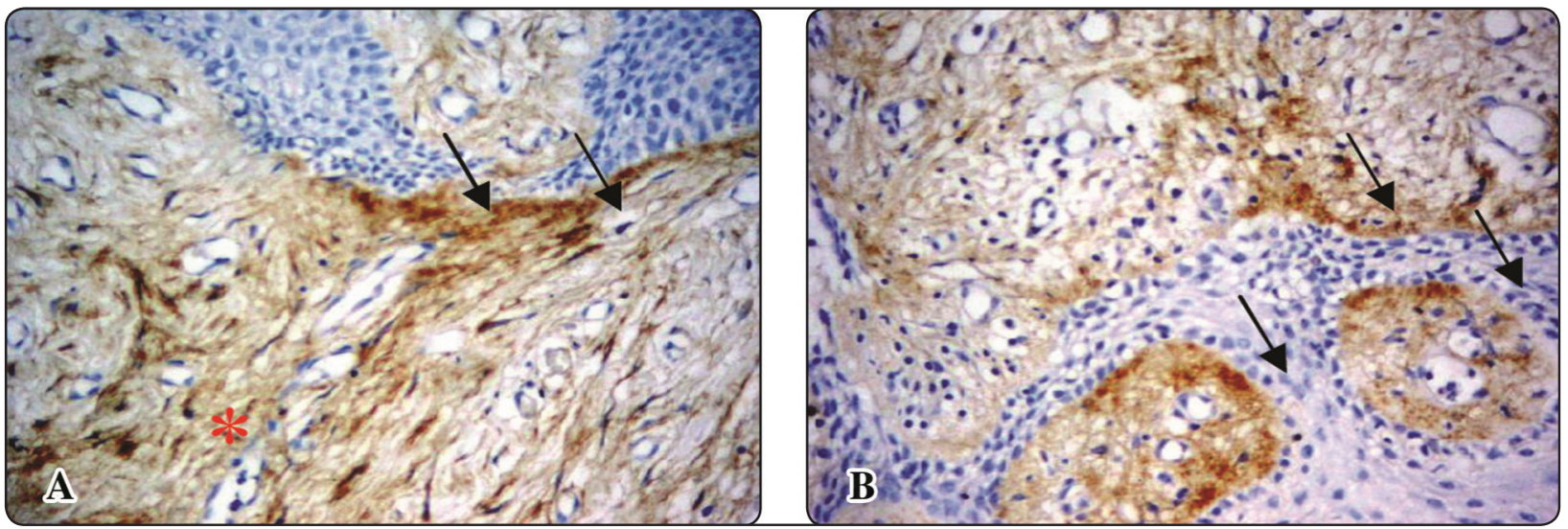

Fig. (4) A, B Fn x200 showing marked deep immunostaining with fibronectin especially at the basement membrane area (arrows) however areas within deep fibrous connective tissue showed deep staining (star) group A

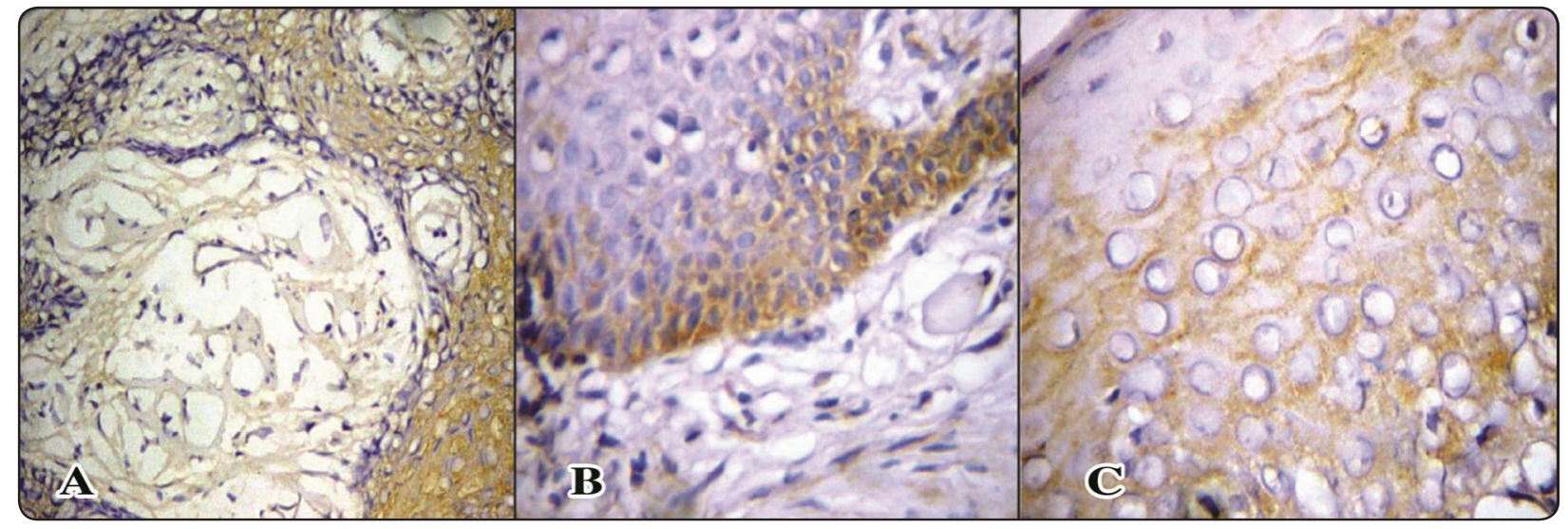

Fig. (5) A. Fn x200 showing generalized marked deep intraepithelial immunoreactions to fibronectin while B. Fn x400 showed deep reaction to basal and suprabasal epithelial layers however some cases showed marked epithelial reaction to Fn in the upper spinous layer figure C. Fn x 400 for cases in group A 
TABLE (1) expressing the numeric value of fibronectin immunostaining to the different cases in the three groups

\begin{tabular}{|c|c|c|}
\hline Group A & Group B & Group C \\
\hline 1 & 3 & 1 \\
\hline 2 & 2 & 1 \\
\hline 3 & 1 & 2 \\
\hline 3 & 1 & 2 \\
\hline 2 & 1 & 1 \\
\hline 1 & 2 & 1 \\
\hline 2 & 2 & 0 \\
\hline 3 & 2 & 1 \\
\hline 2 & & 2 \\
\hline
\end{tabular}

TABLES (2, 3, 4, and 5) show the statistical calculations for the values of the three groups
TABLE (2) Showing mean, standard deviation and standard error means of the three groups

\begin{tabular}{|c|c|c|c|c|}
\hline & Mean & $\mathrm{N}$ & $\begin{array}{c}\text { Std. } \\
\text { Deviation }\end{array}$ & $\begin{array}{c}\text { Std. Error } \\
\text { Mean }\end{array}$ \\
\hline Group A & 2.2000 & 10 & .78881 & .24944 \\
\hline Group B & 1.7000 & 10 & .75341 & .24532 \\
\hline Group C & .9000 & 10 & .73786 & .23333 \\
\hline
\end{tabular}

TABLE (3) Showing correlation between groups A \& C

\begin{tabular}{|l|c|c|c|}
\hline & $\mathrm{N}$ & Correlation & Sig. \\
\hline Group A \& Group C & 10 & .229 & .524 \\
\hline
\end{tabular}

Paired Samples Test

TABLE (4) Showing correlation between groups $\mathrm{B} \& \mathrm{C}$

\begin{tabular}{|c|c|c|c|}
\hline & $\mathrm{N}$ & Correlation & Sig. \\
\hline Group B \& Group C & 10 & .128 & .315 \\
\hline
\end{tabular}

Paired Samples Test

TABLE (5) Showing paired samples test significance

\begin{tabular}{|c|c|c|c|c|c|c|c|c|}
\hline & \multicolumn{5}{|c|}{ Paired Differences } & \multirow{3}{*}{$\mathrm{t}$} & \multirow{3}{*}{ df } & \multirow{3}{*}{$\begin{array}{c}\text { Sig. } \\
(-2 \text { tailed })\end{array}$} \\
\hline & \multirow{2}{*}{ Mean } & \multirow{2}{*}{$\begin{array}{c}\text { Std. } \\
\text { Deviation }\end{array}$} & \multirow{2}{*}{$\begin{array}{c}\text { Std. Error } \\
\text { Mean }\end{array}$} & \multicolumn{2}{|c|}{$\begin{array}{c}\% 95 \text { Confidence Interval of } \\
\text { the Difference }\end{array}$} & & & \\
\hline & & & & Lower & Upper & & & \\
\hline Group A - Group B & 1.30000 & .94868 & .30000 & .62135 & 1.97865 & 4.333 & 9 & $0.002 *$ \\
\hline
\end{tabular}

\section{*Significant $>0.05$}




\section{DISCUSSION}

The pathogenesis of drug-induced gingival overgrowth is multifactorial. Genetic predisposition, pharmacokinetic variables and the presence of dental plaque may all contribute to the changes seen in the gingival tissue ${ }^{(15)}$.

The gingival overgrowth caused by nifedipine administration highlighted its significant role in interdental papilla enlargement. These findings were consistent with the results derived from the experiments on Sprague-Dawley animals, in which gingival growth was dependant on concentration of nifedipine ${ }^{(16)}$.

Gingival growth could be a consequence of the increased number of fibroblasts in the tissue, induced by nifedipine ${ }^{(17)}$. These findings are in agreement with Walsh et, al. $2007{ }^{(15)}$ who confirmed the effect of drug-induced increase in the fibroblastic population in gingival overgrowth, This observation confirms that collagen decomposition is important for physiological remodeling of connective tissue. Nifedipine participation in collagen production may increase the imbalance of collagen degradation as shown by by Romanos et al. ${ }^{(18)}$.

The significant gingival overgrowth in specimens from patients receiving the drug are consistent with the findings of (Myrales et al 1999) ${ }^{(19)}$, Their studies demonstrated that different fibroblast subtypes exist in healthy and hyperplastic gingiva, which react to different stimuli including drugs. Investigations of (Morton et al 1999) ${ }^{(20)}$, showed that nifedipine in combination with dental plaque bacteria, increased interleukin- 6 secretion in the presence of interleukin-1 beta. Interleukin-6 is a cytokine with more than one effect. It has positive effect on the activation and differentiation of $\mathrm{B}$ cells into plasma cells which secrete immunoglobulins. Interleukin-6 is a differentiating factor for cytotoxic T cells, and a growth factor for $\mathrm{B}$ and $\mathrm{T}$ cells, and for mesenchymal cells. It has also been shown that interleukin-6 has stimulates growth and metabolism of connective tissue cells like fibroblasts. We therefore believe that it has pathologic role in diseases where transformations occur on fibroblasts ${ }^{(19)}$.

Gingival fibroblasts secrete considerable amount of interleukin- 6 with or without stimulation, so they might be one of the primary interleukin- 6 sources that received nifedipine ${ }^{(21)}$. It is also possible that nifedipine stimulatory effect is not directly manifested only on the fibroblasts of gingiva, but also causes a complex interaction with dental plaque and inflammatory cytokines. In the presence of nifedipine, fibroblasts will increase the secretion of interleukin-6, resulting in its proliferation and their increased activity, as well as increasing extracellular matrix formation ${ }^{(22)}$.

The histological changes in drug-induced gingival overgrowth tissue include acanthosis, evident as elongated rete ridges, hyperkeratosis and an increase in epithelial width. These features were also confirmed in the present study ${ }^{(23,24)}$.

Epithelial cells are a source of multiple growth factors and cytokines, and have recently been demonstrated to participate actively in connective tissue regulation.

Several previous studies have concentrated on the alterations in gingival connective tissue homeostasis in drug induced overgrowth. Nifedipine appears to have a direct effect on fibroblasts, which may contribute to the pathogenesis of overgrowth, including inhibition of matrix metalliproteinase-1, tissue inhibition of metalloproteinase production, inhibition of collagen phagocytosis, and increased production of transforming growth factor-b and connective tissue growth factor ${ }^{(25,26)}$.

The present study demonstrated that FN was expressed with greater frequency and possibly in an altered distribution (suprabasal expression) in the gingival overgrowth of the drug group when compared with the control group. One possible explanation for the up-regulation of certain integrins may be related to the altered expression of cytokines as a result of the influence of the medication, or because of the direct influence of the medication on the epithelium as demonstrate by Walsh et al (2006) $^{(15)}$ 
Although it is known that integrins and growth factors (GFs) can be costimulatory for fibroblasts ${ }^{(9,10)}$, it has not been previously reported that fibroblast survival requires a coordinate interaction of FN and PDGF-BB, or other GFs. In this regard, it is worth remembering that mesenchymal cell survival requires coordinate interaction of FN with integrins and PDGF-BB with PDGF receptors in their proximity This is not dissimilar to the concept of T-cell multidimensional signaling network stimulation through the immunological synapse and costimulatory pairs in the same nanospace ${ }^{(27)}$

The FN expression in the basal cell layer was greater in the combined drug group when compared with the other drug-induced overgrowth groups and the control group. This is expressed by wound keratinocytes, but not by normal resting keratinocytes ${ }^{(28)}$, and the expression of $\mathrm{FN}$ in the basal keratinocytes is consistent with the observations of Walsh et al (2006) ${ }^{(15)}$ who found that FN was expressed in basal keratinocytes in the gingiva of cases having nifedipine medication.

This pattern of staining was also found around the keratinocytes from intralesional areas of psoriasis. In the non-lesion psoriatic epidermis, it was initially believed that plasma fibronectin leaks into the epidermis from the circulation, ${ }^{(29)}$. Subsequent studies have shown, however, that cellular FN, synthesized in situ by the proliferating keratinocytes, was present at the dermal-epidermal junction in uninvolved psoriasis specimens, but was not present in the control samples ${ }^{(30,31)}$.

The explanation of why $\mathrm{FN}$ is expressed in the basal keratinocytes in drug group remains controversial. However, FN secretion may be due to direct influence of the drug on the keratinocytes ${ }^{(15)}$.

Unexpected reduction of the gingival overgrowth was detectable after a nonsurgical Erbium: YAG laser periodontal treatment of the pseudo-gingival pockets. The conventional surgical treatment using the GO blade has always been a true dilemma for oral surgeons in the past since it is usually characterized by massive intraoperative bleeding, difficult postoperative course for patients, and often recurrence after a short period of time.

The introduction of different laser wavelengths (e.g., erbium: yttrium-aluminum-garnet laser, neodymium: yttrium- aluminum-garnet laser, carbon dioxide laser, and the semiconductor diode laser) for such surgical treatments of soft oral tissues resulted in several advantages for both clinicians and patients. The major benefit of these new lasers has resulted in reduced bleeding or totally avoided during surgery, healing is faster as promoted by laser light photo-biomodulation of the tissues, thus resulting in a high compliance both of adult patients and children. ${ }^{(40,41)}$

More specifically, the Erbium: YAG laser used for periodontal treatments in the presence of gingival pockets, being more selective for water, is able to remove simultaneously calculus from radicular cementum and inflamed soft tissue within the pocket, and to remodel the gingival margins when necessary, promoting decontamination and photo bio modulation of all irradiated surfaces. ${ }^{(42,43)}$

The described case where the unexpected healing of the gingiva occured illustrates a real innovation in the treatment of drug-induced GO. This being the first reported case of CsA related GO treated by Erbium: YAG laser for the nonsurgical periodontal decontamination of the pseudo-gingival pockets obviating the need for excision of gingival overgrowth ${ }^{(43,44)}$

It is now generally acknowledged that, among laser users and scientific societies, Erbium: YAG laser is considered the more appropriate laser modality for the non-surgical periodontal treatments, as this treatment is easy to perform, noninvasive, and well accepted by the patients. ${ }^{(40)}$

In fact, more specifically, Erbium: YAG laser is able to contour and cut the alveolar bone with minimal damage and has high antiseptic effects due to reduction of lipopolysaccharides both in soft and hard tissues. $(3,4)$ Moreover, Erbium: YAG laser 
also induces tissue photo bio modulation, which leads to faster healing as a result of cell proliferation and improved microcirculation. ${ }^{(40)}$

\section{CONCLUSIONS}

Data from the present study confirm that there is a direct correlation between FN expression and nifedipine induced gingival hyperplasia They also suggest that fibronectin plays an important role in the biological process of gingival hyperplasia.

A great part of the scientific community of laser users agreed that Erbium: YAG laser, owing to its intrinsic physical properties, is an excellent tool for periodontal treatments. Based on the results obtained from the present study, we suggest that Erbium: YAG laser may be successfully employed for drug-induced $\mathrm{GO}$ to decrease the integrin expression in the soft tissue thus reducing the need for surgical intervention in GO treatment owing to the simplicity of this technique and the increased compliance of the patient. It is anticipated that wider adoption of such non-invasive and effective treatment protocol will establish Erbium: YAG laser as an effective treatment for $\mathrm{GO}$, as well as for periodontal maintenance in such patients and for recurrence of GO. Further reports and clinical studies are still needed.

\section{SUMMARY}

This report focuses the attention on a new procedure for the management of drug-induced GO that remains a frequent complication of several drug therapies (immunosuppressive agents, anti-epileptics, and calcium channel blockers), exacerbated by plaque and calculus accumulation. Erbium: YAG laser treatment associated with the conventional calculus scaling could be considered a new modality for the nonsurgical treatment of druginduced GO, promoting a good patient compliance, rendering surgical procedures for gingival excision/ reduction no longer necessary.

\section{ACKNOWLEDGEMENT}

Authors would like to acknowledge Prof. Amr Helmy El_Bolok,Professor of Oral and Maxillofacial Pathology, Faculty of Dentistry, Minia University, Minia, Egypt

\section{REFERENCES}

1. Abdollahi M. and Radfar M.: A review of drug-induced oral reactions. J Contemp Dent Pract 2003; 4(1): 10-31.

2. Zlata B.: Influence of nifedipine on gingiva of Wistar rats Brkic Z. Vojnosanit Pregl 2004; 61(1): 5-8.

3. Brunet L., Miranda J., Farre M., Berini L.and Mendieta C.:Gingival enlargement induced by drugs. Drug Saf 1996; 15(3); 219-31.

4. Desai P.and Silver J.G.: Drug-induced gingival enlargements.J Can Dent Assoc 1998; 64(4); 263-8.

5. McClain S.A, Simon M. and Jones E.: Mesenchymal cell activation is the rate limiting step of granulation tissue induction. Am J Pathol ; 1996; 149:1257-70

6. Zhang Z., Vuori K. and Reed J.C.: The alpha 5 beta 1 integrin supports survival of cells on fibronectin and upregulates Bcl-2 expression. Proc Natl Acad Sci USA 1995; 92: 61-5

7. Ilic D, Almeida EA and Schlaepfer D.D.: Extracellular matrix survival signals transduced by focal adhesion kinase suppress p53-mediated apoptosis. J Cell Biol.; 1998; 143:547-60.

8. Romashkova J.A. and Makarov S.S.: NF-kappaB is a target of AKT in antiapoptotic PDGF signalling. Nature; 1999; 401:86-90.

9. Plopper G.E., McNamee H.P. and Dike L.E.: Convergence of integrin and growth factor receptor signaling pathways within the focal adhesion complex. Mol Biol Cell; 1995; 6:1349-65.

10. Miyamoto S., Teramoto H. and Gutkind J.S.: Integrins can collaborate with growth factors for phosphorylation of receptor tyrosine kinases and MAP kinase activation: roles of integrin aggregation and occupancy of receptors. J Cell Biol.; 1996; 135:1633-42.

11. Assoian R.K. and Schwartz M.A.: Coordinate signaling by integrins and receptor tyrosine kinases in the regulation of G1 phase cell-cycle progression. Curr Opin Genet Dev; $2001 ; 11: 48-53$. 
12. Fubao L., Xiang-Dong R., Zhi P., Lauren M., WeiXing Z., Marcia G., Miriam R., Dafna B. and Richard A.: Fibronectin Growth Factor-Binding Domains Are Required for Fibroblast Survival. Journal of Investigative Dermatology ; 2011; Volume 131.

13. Renshaw M.W., Ren X.D. and Schwartz M.A.: Growth factor activation of MAP kinase requires cell adhesion. EMBO J.; 1997; 16:5592-9.

14. Greiling D. and Clark R.A.: Fibronectin provides a conduit for fibroblast transmigration from a collagen gel into a fibrin gel. J. Cell Sci. ; 1997; 110(Part 7):861-70

15. Walsh P, Häkkinen L., Pernu H., Knuuttila M. and Larjava H.: Expression of fibronectin binding integrins in gingival epithelium in drug-induced gingival overgrowth. J. Periodont Res; 2007; 42: 144-151.

16. Henderson J.S., Flynn J.C., Tucci M.A., Tsao A.K., Zebrowsici E.J. and Odium O.: Site-specific variations in metabolism by human fibroblasts exposed to nifedipine in vitro. J. Oral Pathol. Med.; 1997; 26(1); 6-10.

17. Ingles E., Rossmann J.A.and Cajfesse R.G.: New clinical index for drug-induced gingival overgrowth. Quintessence Int.; 1999; 30(7); 67-73.

18. Romanos G.E., Schroter-Kermani C., Hinz N., Herrmann D., Strub J.R. and Bernimoulin J-P.: Extracellular matrix analysis of nifedipine-induced gingival overgrowth: immunohistochemical distribution of different colktgen types as well as the glycoprotein fibronectin. J. Periodont. Res.; 1993; 28: 10-16.

19. Myrillas T.T., Linden G.J., Marley J.J. and Irwin C.R.: Cyclosporine A regulates interleukin-1 beta and interleukin-6 expression in gingiva; implications for gingival overgrowth J Periodontol 1999; 70(3); 294-300.

20. Morton R.and Dongari-Bagtzoglou A.: Regulation of gingival fibroblast interleukin-6 secretion by cyclosporineJ Periodontol; 1999; 70(12): 1464-71.

21. Nohl F. and Ferrari P.: Drug-induced gingival hyperplasia. Ther. Umsch.; 1998; 55(9); 573-5.

22. Seggev J.S and Lagstein Z.: Photosensitivity skin reactions to calcium channel blockers. J. Allergy Clin. Immunol.; 1996; 97(3); 852-5.

23. Marshall R.I. and Bartold P.M.: Medication induced gingival overgrowth. Oral Dis.; 1998; 4:130-151.

24. Van der Wall E.E., Tuinzing D.B. and Hes J. : Gingival hyperplasia induced by nifedipine, an arterial vasodilating drug. Oral Surg. Oral Med. Oral Pathol.: 1985; 60:38-40.
25. Uzel M.I., Kantarci A.and Hong H.H.: Connective tissue growth factor in drug induced gingival overgrowth. J Periodontol.; 2001;72:921-931.

26. Yamada H., Nishimura F. and Naruishi K.: Phenytoin and cyclosporin A suppress the expression of MMP-1, TIMP1, and cathepsin $\mathrm{L}$, but not cathepsin $\mathrm{B}$ in cultured gingival fibroblasts. J. Periodontol.; 2000; 71: 955-960.

27. Tseng S.Y. and Dustin M.L.: T-cell activation: a multidimensional signaling network. Curr. Opin. Cell Biol.; 2002; 14:575-80

28. Larjava H., Salo T., Haapasalmi K., Kramer R.H. and Heino J.: Expression of integrins and basement membrane components by wound keratinocytes. J. Clin. Invest.; 1993; 92: 1425-1435.

29. Bata-Csorgo Z., Cooper K.D., Ting K.M., Voorhees J.J. and Hammerberg C.: Fibronectin and a5 integrin regulate keratinocyte cell cycling. A mechanism for increased fibronectin potentiation of $\mathrm{T}$ cell lymphokinedriven keratinocyte hyperproliferation in psoriasis. J. Clin. Invest.; 1998;101:1509-1518.

30. Ting K.M., Rothaupt D. and McCormick T.S.: Overexpression of the oncofetal Fn variant containing the EDA splicein segment in the dermal-epidermal junction of psoriatic uninvolved skin. J. Clin. Invest.; 2000; 114:706-711.

31. Szell M., Bata-Csorgo Z. and Koreck A.: Proliferating keratinocytes are putative sources of the psoriasis susceptibilityrelated EDA+ (extra domain A of fibronectin) oncofetal fibronectin. J. Invest. Dermatol.; 2004;123:537- 546.

32. Seymour RA, Thomason JM, Ellis JS. The pathogenesis of drug induced gingival overgrowth. J Clin Periodontol 1996;23:165-175

33. Andrukhov O, Matejka M, Rausch-Fan X. Effect of cyclosporine A on proliferation and differentiation of human periodontal ligament cells. Acta Odontol Scand 2010;68:329-334.

34. Ishikawa I, Aoki A, Takasaki AA. Potential applications of Erbium:YAG laser in periodontics. J Periodontal Res 2004; 39:275-285.

35. Pourzarandian A, Watanabe H, Ruwanpura SM, Aoki A, Ishikawa I. Effect of low-level Er:YAG laser irradiation on cultured human gingival fibroblasts. J Periodontol 2005;76:187-193

36. Matarese G, Ramaglia L, Cicciu` M, Cordasco G, Isola G. The effects of diode laser therapy as an adjunct to scaling and root planing in the treatment of aggressive period- 
FIG. 5. After 2 months, during clinical follow-up, no signs of periodontal inflammation were detectable and gingiva showed a normal appearance; for this reason, no additional surgical procedure has been necessary. ERBIUM:YAG AND GINGIVAL OVERGROWTH 55 Downloaded by 105.44.98.20 from www.liebertpub.com at 09/27/20. For personal use only. ontitis: a 1-year randomized controlled clinical trial. Photomed Laser Surg 2017;35:702-709.

37. Chen CK, Wu YT, Chang NJ, et al. Er:YAG laser for surgical crown lengthening: a 6-month clinical study. Int J Periodontics Restorative Dent 2017;37:e149-e153.

38. Isola G, Matarese G, Lo Giudice G, et al. A new approach for the treatment of lateral periodontal cysts with an 810-nm diode laser. Int J Periodontics Restorative Dent 2017;37:e120-e129.

39. Saverio Capodiferro, et al., Nonsurgical Periodontal Treatment by Erbium: YAG Laser Promotes Regression of Gingival Overgrowth in Patient Taking Cyclosporine A: A Case Report. Photobiomodulation, Photomedicine, and Laser Surgery, Volume 37, Number 1, 2019
40. Gontiya G, Bhatnagar S, Mohandas U, Galgali SR. Laserassisted gingivectomy in pediatric patients: a novel alternative treatment. J Indian Soc Pedod Prev Dent 2011; 29:264-269.

41. Kumar P, Rattan V, Rai S. Comparative evaluation of healing after gingivectomy with electrocautery and laser. J Oral Biol Craniofac Res 2015;5:69-74.

42. Kuo PJ, Tu HP, Chin YT, et al. Cyclosporine-A inhibits MMP-2 and -9 activities in the presence of Porphyromonas gingivalis lipopolysaccharide: an experiment in human gingival fibroblast and U937 macrophage co-culture. J Periodontal Res 2012;47:431-438.

43. Vladimirov IuA, Klebanov GI, Borisenko GG, Osipov AN. Molecular and cellular mechanisms of the low intensity laser radiation effect. Biofizika 2004;49:339-350.

44. Maddi A, Alluri LS, Ciancio SG. Management of gingival overgrowth in a cardiac transplant patient using laser-assisted gingivectomy/gingivoplasty. J Int Acad Periodontol 2015;17:77-81. 